\title{
HALLUCINATIONS AFTER VALPROIC ACID WITHDRAWAL
}

Child psychiatrists and neurologists in Utrecht, The Netherlands report case histories of 2 girls, ages 4 and 12 years, with a history of epilepsy who developed hallucinations after withdrawal of valproic acid (VPA). The 4-year-old woke up at night and complained of seeing and hearing snakes in her bed, and the 12-year-old heard voices and saw nonexisting persons. When VPA was restarted the hallucinations rapidly disappeared. The hallucinations were explained by enhancement of dopaminergic neurotransmission elicited by a decrease of GABA or rebound of glutaminergic activity after rapid withdrawal of VPA. A possible role of VPA in controlling a predisposition to hallucinations is suggested. (de Laat SAA, Hillegers MHJ, Jansen FE, Braun KP, de Graeff-Meeder ER. Hallucinations after withdrawal of valproic acid. Pediatrics 2012 Jul;130(1):e236-8). (Respond: Elizabeth R de Graeff-Meeder, Heidelberglaan 100, 3584 CX Utrecht, The Netherlands. E-mail: b.degraeff@umcutrecht.nl).

COMMENT. The antiepileptic activity of VPA has several proposed mechanisms, including the enhancement of GABA. Increased dopamine release due to decreased GABA activity is suggested as a cause of hallucinations after VPA withdrawal.

\section{FENFLURAMINE ADD-ON THERAPY OF DRAVET SYNDROME}

Researchers at Antwerp University Hospital and University of Leuven, Belgium report 12 patients, 7 female and 5 male, age range 3-35 years, with a genetically proven diagnosis of Dravet syndrome who received fenfluramine (mean dose 0.34 (0.12-0.90) $\mathrm{mg} / \mathrm{kg} /$ day) as add-on therapy. Seven (58\%) patients had been seizure free for a mean of 6 (1-19) years. When fenfluramine treatment was discontinued in 7 patients, seizures recurred in 3; seizures were controlled when fenfluramine was reintroduced. Two patients developed a mild thickening of one or two cardiac valves without clinical symptoms. (Ceulemans B, Boel M, Leyssens K, et al. Successful use of fenfluramine as an add-on treatment for Dravet syndrome. Epilepsia 2012 Jul;53(7):1131-9). (Respond: Berten Ceulemans MD, PhD, Department of Neurology-Pediatric Neurology, Antwerp University Hospital, Wilrijkstraat 10, B 2650 Edegem, Belgium. E-mail: berten.ceulemans@uza.be).

COMMENT. Fenfluramine is a substituted phenylethylamine structurally related to amphetamine. The combination "Fen-Phen" anti-obesity product was withdrawn from the market in the US in 1997 because of serious cardiac side effects. The effectiveness of fenfluramine in treatment of self-induced photosensitive epilepsy was reported in 1985 (Aicardi J, Gastaut H. N Engl J Med 1985 Nov 28;313(22):1419) and confirmed in 1996 (Boel M, Casaer P. Neuropediatrics 1996 Aug;27(4):171-3).

The use of stimulants in the treatment of epilepsy is not new. In 1942, Cook and Dole report the effectiveness of dl-amphetamine (Benzedrine) (Cook GH, Dole JA. Dis Nerv Syst 1942 Nov;3:366-370), and in 1955, the classic, Goodman and Gilman textbook includes reference to the control of "petit mal" and the associated EEG spike and wave discharges following d-amphetamine (Dexedrine). (Goodman LS, Gilman A. The Pharmacological Basis of Therapeutics. $2^{\text {nd }}$ Ed, New York, Macmillan, 1955). 